\title{
Realization of high-efficiency and high-output characteristics of magnetic power generators using single-phase angle transformation and three-phase six-wire winding
}

\author{
Ching-Chuan $\operatorname{Lin}^{1}$ (1) $\cdot$ Chang-Ren Chen ${ }^{1}$
}

Received: 11 January 2019/Accepted: 30 March 2019/Published online: 6 April 2019

(c) The Author(s) 2019

\begin{abstract}
Taiwan's electricity consumption during summer increases significantly owing to the abnormal climatic changes caused by the greenhouse effect. An expedient strategy to develop a high-efficiency magnetic power generator can address the existing problem of power shortage in Taiwan. The magnetic power generator uses the force between the polarity of the magnet and the induced magnetic field of the coil to generate suction and thrust forces, which are generated when a magnet enters and leaves the coil, respectively, and can reduce the motor power consumption to achieve an energy saving effect. From the viewpoint of single-phase magnetic power generators, an angle transformation arrangement is used to achieve a positive power output to maximize the power efficiency, and three-phase power generation is used to maximize the output, where 8 magnets and 12 six-wire wound coils are used in conjunction with a delta or Y connection to achieve three-phase output. Each phase is $120^{\circ}$ out of phase and each phase has 4 coils that generate power per revolution simultaneously. The high output characteristic enables the use of the three-phase magnetic power generators in several industrial applications. Herein, for a single-phase power generator, 8 magnets and 10 wires were used in an angle transformation arrangement, which achieved an output efficiency of up to $129.7 \%$, whereas the three-phase power generator with 8 magnets and 12 sixwire wound coils with a diameter of $0.4 \mathrm{~mm}$ were used in conjunction with a delta or Y connection and achieved, which achieved an output efficiency of up to $82 \%$, indicating that both these generators can be used for emergency power generation in homes, factories, or hospitals.
\end{abstract}

\section{Introduction}

\subsection{The trend of single-phase and three-phase magnetic assisted power generator}

Currently, the traditional generators are driven by a large motor due to the large load resistance, which causes a lot of energy to be wasted. A magnetic power generator improves power generation efficiency using magnetic energy to reduce load resistance, which allows the use of a small motor. For the single-phase generator, the coils enabled a positive efficiency output through an angle transformation arrangement, whereas for the three-phase generator, the 6 wire winding method was employed to generate a large

Ching-Chuan Lin

ching511008@gmail.com; aaas5310@yahoo.com.tw

1 Mechanical Engineering Department, Kun Shan University, Tainan 710, Taiwan amount of energy, which could mitigate the problem of power shortage in Taiwan.

\subsection{The principle of magnetic generator}

\subsubsection{Fleming's right hand rule}

As shown in Fig. 1, the thumb gives the direction of the magnetic field and the other 4 fingers provide the coil current direction, indicating that the experimental results were in agreement with the right-hand rule.

\subsubsection{Explanation of the principle of generating magnetic force by coils arranged in a lateral direction using clockwise wire winding method}

Figure 2 indicates that when the clockwise wound coils were arranged in a lateral direction, the $\mathrm{N}$-pole of the magnet entering the side coil was still the N-pole, which 
Magnetic force principle introduction

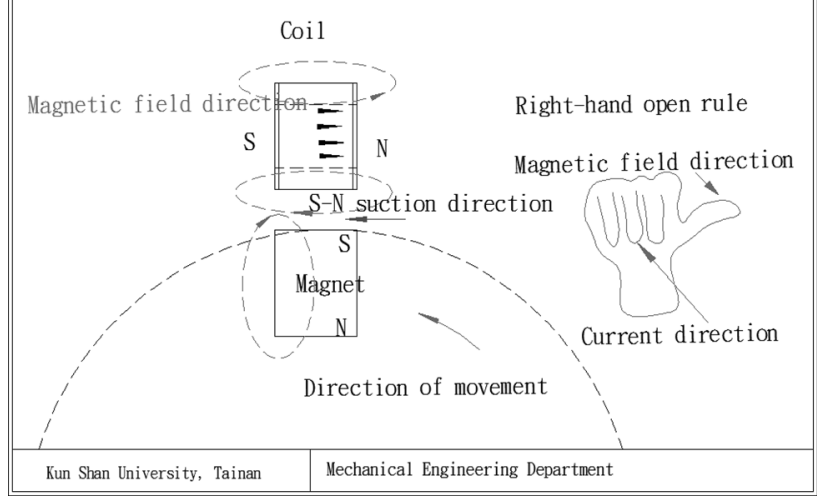

Fig. 1 Direction of current and magnetic field with Fleming's right hand rule right-hand opening law

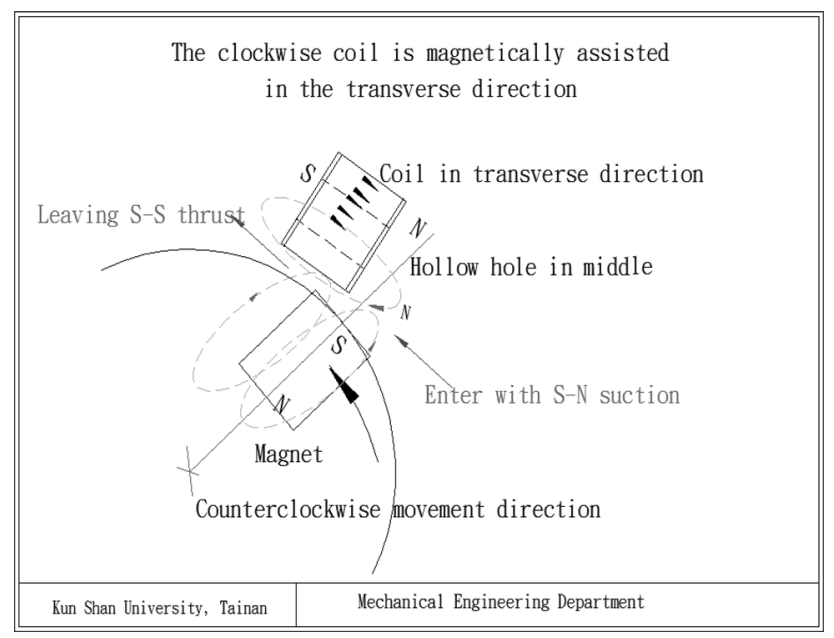

Fig. 2 Magnetic assist coil in the horizontal direction magnetic assist principle

generated SN suction with the S-pole of the magnet. When the magnet left the side coil, SS thrust is generated due to the opposite magnetic field (Siclafi 1993).

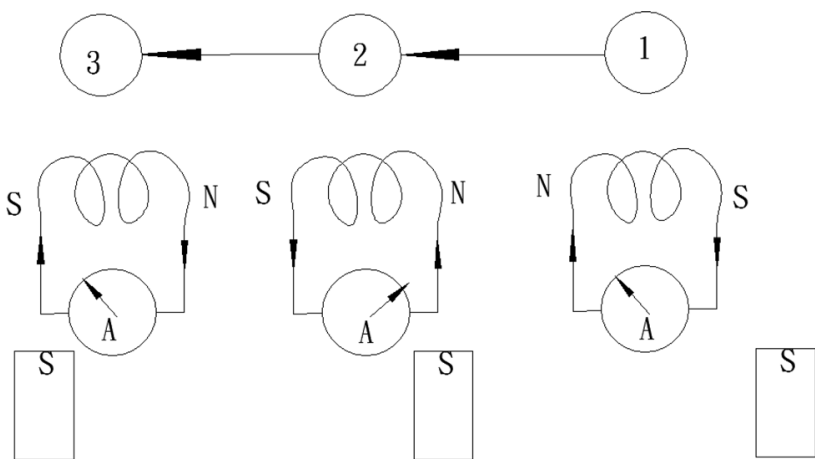

Fig. 3 Using the pointer-type galvanometer to illustrate the principle of magnetic assistance in straight direction
As can be seen in Fig. 3, for the clockwise wound coils arranged in a lateral direction, when the magnet is approaching, a potential resistance was generated due to the generation of a reverse bias, which was indicated by the pointer of the volt-ohm-ammeter (position 1). When the magnet reached the coil, suction was generated due to the generation of a forward bias, indicated by the pointer of the volt-ohm-ammeter (position 2). When the magnet was leaving, thrust (Konrad 1992) was generated due to the generation of a reverse bias, indicated by the pointer of the volt-ohm- ammeter (position 3).

\subsubsection{Explanation of the principle of generating magnetic force by coils arranged in a longitudinal direction using clockwise wire winding method}

As can be seen in Fig. 4, the CW wire was wound clockwise from left to right. When the $\mathrm{CW}$ wound magnetic assist coils were arranged in a vertical direction with the magnet entering the power induction coil, the $S$ pole of the coil changed to the $\mathrm{N}$ pole, generating SN suction. When the magnet reached to middle the middle of the coil, the pole of the power generating coil was restored to the $\mathrm{S}$ pole due to the opposite magnetic field, thus generating SS thrust (Siclafi 1993).

Figure 5 shows that with the red and black rods of the volt-ohm- ammeter connected to the $\mathrm{S}$ and $\mathrm{N}$ poles, respectively, when the $\mathrm{S}$ pole magnet was approaching, a forward current bias were generated, indicating the generation of a NS magnetic field. When the S pole magnet was leaving, a reverse current bias was generated in the volt-ohm- ammeter, indicating the generation of a SS magnetic field (Konrad 1992).

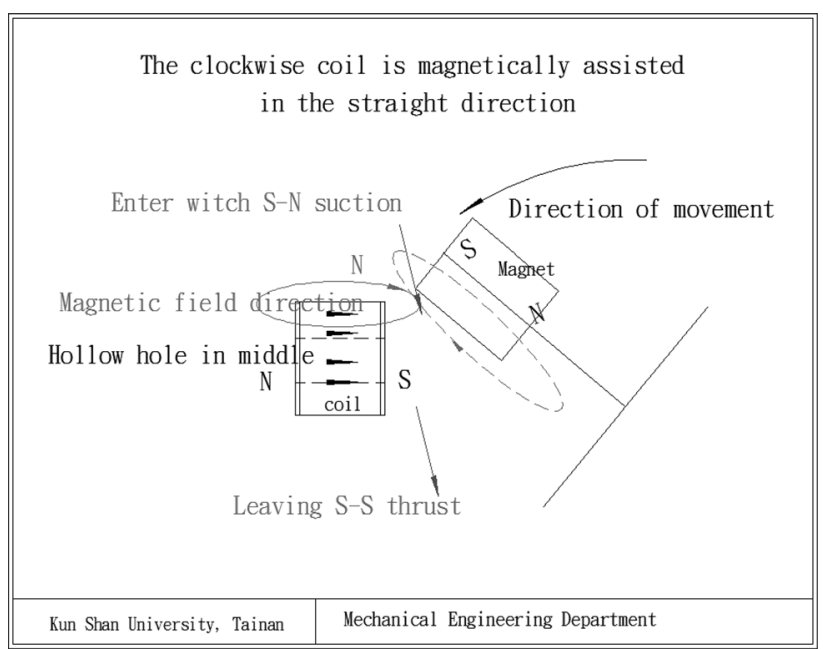

Fig. 4 Analysis of magnetic assist force generated by coils arranged in a longitudinal direction 
Using the three-meter meter to illustrate the principle of magnetic assistance

Magnetic field direction

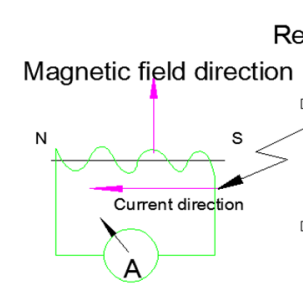

Red rod of meter

Reverse bias current direction

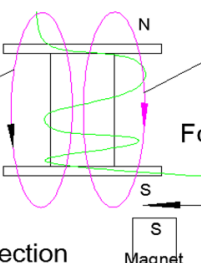

Magn

Fig. 5 Using the volt-ohm-ammeter pointer to illustrate the principle of magnetic assist force generated by coils arranged in a vertical direction

\section{Experimental}

\subsection{High efficiency of single-phase magnetic assisted generator}

\subsubsection{Single-phase generator with coils arranged}

in a normal angle (Cheng et al. 2011; Ishak 2004)

2.1.1.1 Calculation of weight, length, and the number of turns of power coil (Cheng and Evans 1994) Power coil having a wire diameter of $0.04 \mathrm{~cm}$ and each coil weighing $250 \mathrm{~g}$, was denoted as $\mathrm{D}$, where the enameled wire density (d) was $9 \mathrm{~g} / \mathrm{cm}^{3}$. The length of the wire corresponding to $1000 \mathrm{~g}$ could be solved by substituting $1000 \mathrm{~g}$ into the following equation,

$\frac{1000 \mathrm{~g} / 10 \mathrm{~cm}}{\frac{\pi}{4} \times 0.04^{2} \mathrm{~cm}^{2} \times 9 \mathrm{~g} / \mathrm{cm}^{2}}=884(\mathrm{M})$.

Currently each coil weighs $250 \mathrm{~g}$. Thus the length was calculated as $221 \mathrm{M}(884 \mathrm{M} \div 4)$.

The number of turns corresponding to the length of $221 \mathrm{~m}$ was calculated (the middle value for the inner and outer diameter was taken)

The circumference of each coil $=3.14 \times$ $0.03 \mathrm{M}=0.0942 \mathrm{M}$

The number of turns was calculated as 2346 $(221 \mathrm{M} \div 0.0942 \mathrm{M}=2346)$

\subsubsection{Maximum power generation estimate calculation} (Saha et al. 2006) Total impedance was $0.24 \mathrm{~K} \Omega$. Total coil voltage for maximum power generation can be calculated using the following formula:

$\varepsilon_{0}=2 \pi \mathrm{NBAf}$,

where $\mathrm{N}=$ the number of coil turns, $\mathrm{B}=$ magnetic flux density (magnetic field; unit: $\mathrm{T}$ ), $\mathrm{A}=$ coil contact area

(cross-sectional area; unit: $M^{2}$ ), and $\mathrm{f}=$ frequency $(\mathrm{Hz})$.

$1 \mathrm{~T}=10^{4}$ gauss; currently $\mathrm{N} 48$ magnets with a magnetic flux of $0.04 \mathrm{~T}$ were used; a coil had a contact area of $1.5 \mathrm{~cm}^{2}=0.015 \mathrm{~cm}^{2} \mathrm{M}^{2}$; and the number of coil turns $(\mathrm{N})=2346$ (based on prior calculation).

Frequency was calculated as follows: it was known that each coil generated electricity 8 times per revolution. The idling speed $=2046 \mathrm{rpm}$ or $34.1 \mathrm{r}$ ps. Therefore, $\mathrm{f}=34.1 \times 8=272 \mathrm{~Hz}$, which was substituted into the formula of $\varepsilon_{0}$

$$
\begin{aligned}
\varepsilon_{0} & =2 \times 3.14 \times 2346 \times 0.04 \mathrm{~T} \times 0.015^{2} M^{2} \times 272 \mathrm{~Hz} \\
& =36 \mathrm{~V} \mathrm{AC}(\text { power generated by each power generating coil }) .
\end{aligned}
$$

Power generated by 8 coils $=36 \mathrm{~V} \times 8=288 \mathrm{~V}$

2.1.1.3 Test 1: Single-phase generator with coils arranged in a normal angle Test 1: A DC $300 \mathrm{~W}$ brushless motor with a load of $12 \mathrm{~V}$ with the diameter and length of the magnets $25 \times 25$ N48-based single-phase magnets arranged in a normal angle and the diameter $0.4 \mathrm{~mm}$-based coils was tested in conjunction with $13 \mathrm{~W}$ LEDs. The configuration is shown in Fig. 6.

In Fig. 7, the single-phase generator with coils in a normal angle arrangement and all are arranged in a horizontal direction (Ishak 2004).

Test1 mainly tests the efficiency of the single-phase normal angle arrangement magnetic assisted positive output, and compares the difference between the actual power generation and the theoretical power generator.

Table 1 shows that, with a power input of $21 \mathrm{~W}$, the output of the single-phase generator with coils in a normal arrangement is $15.19 \mathrm{~W}$, which failed to achieve the

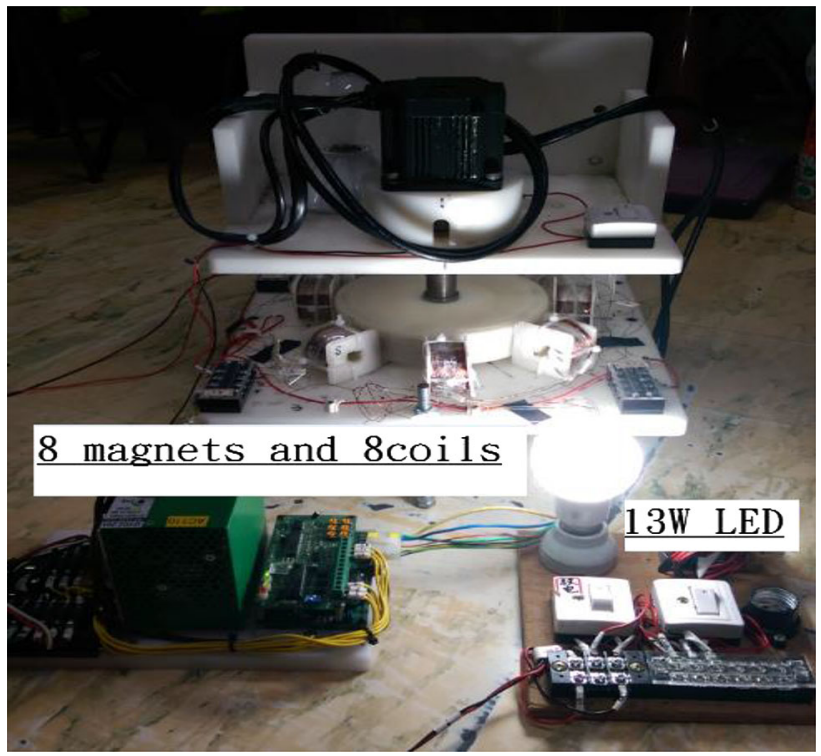

Fig. 6 Single-phase 8 magnets and 8 coil entities 


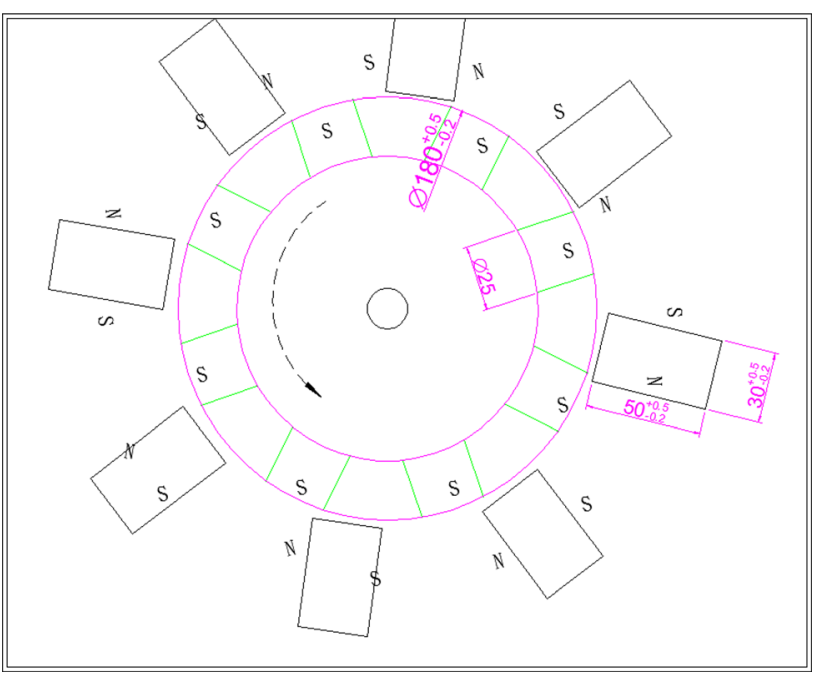

Fig. 7 Single-phase generator with coils arranged in a normal angle

Table 1 Mainly test the efficiency of the single-phase normal angle arrangement magnetic assisted positive output, and compare the difference between the actual power generation and the theoretical power generator

\begin{tabular}{ll}
\hline High-power load & $13 \mathrm{~W}$ LED \\
\hline No-load 2047 rpm input & $8.7 \mathrm{VAC} \times 0.81 \mathrm{~A} \times \sqrt{ } 3 \times 0.8=9.76 \mathrm{~W}$ \\
No-load output & $250 \mathrm{VAC}$ \\
Load input & $8.6 \mathrm{VAC} \times 1.77 \mathrm{~A} \times \sqrt{ } 3 \times 0.8=21 \mathrm{~W}$ \\
Load 1975 rpm output & $217 \mathrm{VAC} \times 0.07 \mathrm{~A}=15.19 \mathrm{~W}$ \\
elf & $15.19 \mathrm{~W} \div 21 \mathrm{~W}=72 \%$ \\
Power consumption & $21 \mathrm{~W}-9.76 \mathrm{~W}=11.24 \mathrm{~W}$ \\
Net power & $15.19 \mathrm{~W}-11.24 \mathrm{~W}=3.95 \mathrm{~W}$ \\
Net output & $3.95 \mathrm{~W}-9.76 \mathrm{~W}=-5.81 \mathrm{~W}$ \\
\hline
\end{tabular}

positive magnetic assist efficiency. Experimental results indicated that the theoretical maximum power generation voltage was $288 \mathrm{~V} \mathrm{AC}$, whereas, when the actual test speed reached $2047 \mathrm{rpm}$, the maximum power generation voltage was $250 \mathrm{~V} \mathrm{AC}$, indicating that the error value was $38 \mathrm{~V}$ AC $(288 \mathrm{~V}-250 \mathrm{~V}=38 \mathrm{~V}$ AC). Such a small error value verified the accuracy of the theoretical power generation.

\subsubsection{Single-phase generator with coils in an angle transformation arrangement}

Test 2: Single-phase generator with coils in an angle transformation

In Fig. 8, the coils were arranged in an angle transformation, where 6 coils were arranged in a lateral direction, and the left and right coils were arranged in a longitudinal direction. The left vertical coil is opposite in polarity to the right vertical coil. Therefore, these coils need to advance

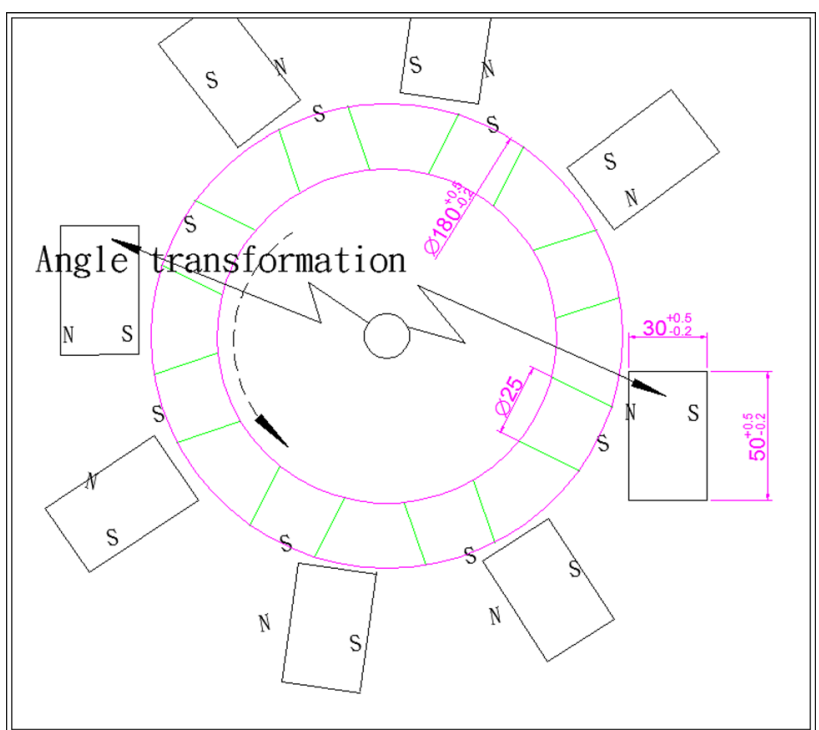

Fig. 8 Single-phase generator with coils in angle transformation

by one position to achieve the in-phase condition to simultaneously generate positive phase voltage (Zhang and Tang 2014).

As can be seen from Table 2, with an input of $19 \mathrm{~W}$, the single-phase generator with coils in an angle transformation arrangement enables an output of $21 \mathrm{~W}$, verifying that the magnetic assistance could help to achieve positive output efficiency, which indicated that the angle transformation arrangement could achieve a great effect (Fig. 9).

\subsubsection{Single-phase generator with coils in an angle transformation arrangement}

Test 3: Reverse-phase voltage coils incorporated into a single-phase generator with magnets in an angle transformation arrangement

Table 2 Results of efficiency and positive output of magnetic power generator with coils in an angle transformation arrangement, and comparison of power generation of generator with coils in an angle transformation arrangement and that of the generator with coils in a normal arrangement

\begin{tabular}{ll}
\hline High-power load & $13 \mathrm{~W}$ LED \\
\hline No-load 2057 prpm input & $8.7 \mathrm{VAC} \times 0.66 \mathrm{~A} \times \sqrt{3} \times 0.8=8 \mathrm{~W}$ \\
No-load output & $185 \mathrm{VAC}$ \\
Load input & $8.6 \mathrm{VAC} \times 1.6 \mathrm{~A} \times \sqrt{3} \times 0.8=19 \mathrm{~W}$ \\
Load 1985 rpm output & $229 \mathrm{VAC} \times 0.091 \mathrm{~A}=21 \mathrm{~W}$ \\
elf & $21 \mathrm{~W} \div 19 \mathrm{~W}=110 \%$ \\
Power consumption & $19 \mathrm{~W}-8 \mathrm{~W}=11 \mathrm{~W}$ \\
Net power & $21 \mathrm{~W}-11 \mathrm{~W}=10 \mathrm{~W}$ \\
Net output & $10 \mathrm{~W}-8 \mathrm{~W}=+2 \mathrm{~W}$ \\
\hline
\end{tabular}




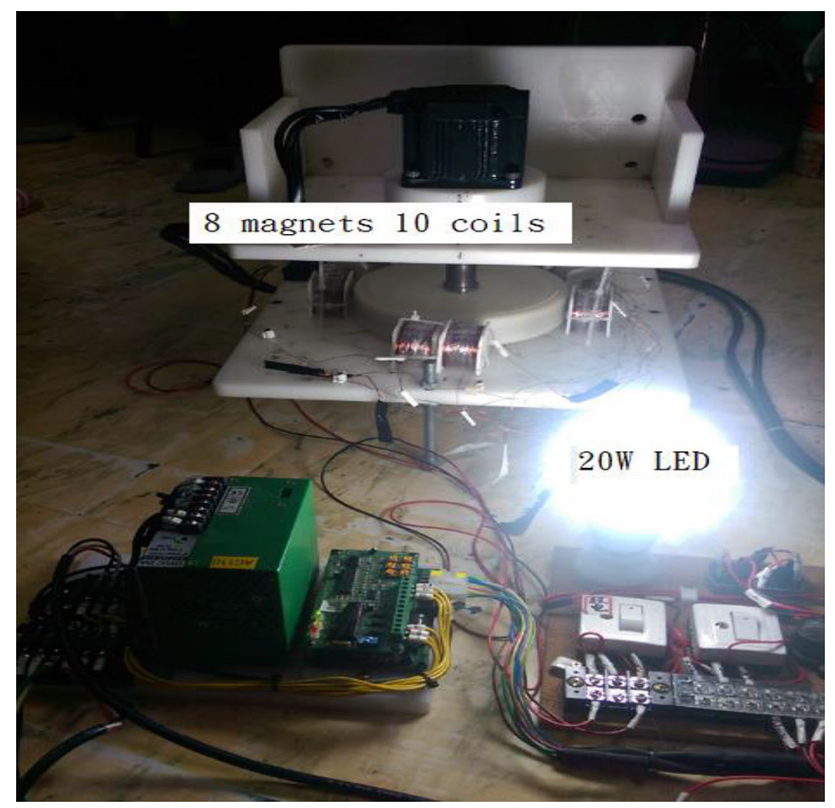

Fig. 9 Reverse-phase voltage coils incorporated into a single-phase generator with magnets in an angle transformation arrangement

In Fig. 10, the reverse-phase voltage coils are incorporated into a single-phase generator with coils in an angle transformation arrangement, where 8 coils were arranged in a lateral direction, and the left coil and right coil were arranged in a vertical direction. The left vertical coil is opposite in polarity to the right vertical coil. Therefore, the left vertical coil needs to advance by one position to be in phase with its right vertical counterpart to simultaneously generate positive phase voltage, and meanwhile in the next in-phase period, to increase the reverse-phase voltage (Ooiwa and Vehicle 2003).

As can be seen from Table 3, with an input of $26.9 \mathrm{~W}$, the single-phase generator with reverse-phase voltage coils

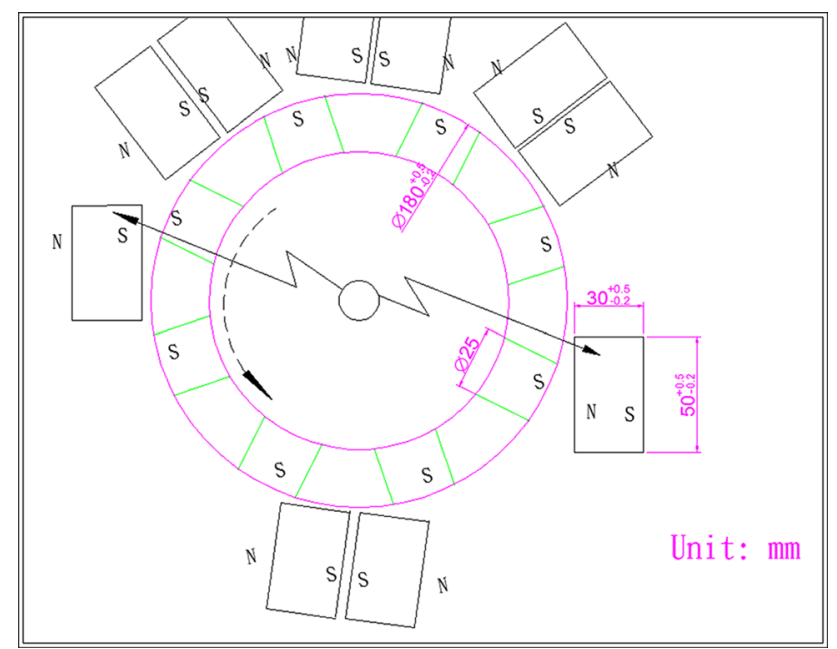

Fig. 10 Reverse-phase voltage coils incorporated with a single-phase generator with magnets in an angle transformation arrangement was incorporated into magnets in an angle transformation arrangement achieves an output of $34.9 \mathrm{~W}$, indicating that the high positive output $8 \mathrm{~W}$ is achieved. This device could be used in electric vehicles to increase the driving endurance.

\subsection{Three-phase generator with high output power generation}

\subsubsection{Three-phase power generator in delta connection}

Test 4: 8 magnets and 12 coils were tested, where all 12 three-phase coils in delta connection are arranged in a longitudinal direction (Fig. 11).

In Fig. 12, 8 magnets and 12 coils are in three-phase delta or $\mathrm{Y}$ connection, where the difference of each phase is $120^{\circ}$ and 4 coils simultaneously generate power in each phase.

In Fig. 13, a wire head in one phase must be connected to a wire tail in another phase to generate three-phase 220 V AC voltage (Salmeron and Litran 2010).

As can be seen form Table 4, with an input of $86.2 \mathrm{~W}$, the generator with 8 magnets and 12 vertical arrangementbased coils connected in three-phase delta connection achieves an output of $52.14 \mathrm{~W}$, indicating an efficiency of $60 \%$.

\subsubsection{Test 5: Three-phase generator in $Y$ connection}

Test 5: The generator with 8 magnets and 12 coils in threephase $\mathrm{Y}$ connection is tested, where the coils are all arranged in a longitudinal direction.

As can be seen from Fig. 14, in the three-phase Y connection, the N-pole wire tails are connected with one another to achieve a three-phase voltage balance, thus generating 220 and $440 \mathrm{~V}$ AC voltages (Sreenivasarao et al. 2012).

Table 3 Results of positive output efficiency of the single-phase magnetic power generator with reverse-phase coils and coils in an angle transformation arrangement, and comparison of power generation of the reverse-phase voltage-based generator with coils with and without an angle transformation arrangement $(0.26 \mathrm{~K} \Omega)$

\begin{tabular}{ll}
\hline High-power load & 20 W LED \\
\hline No-load 1916 rpm input & 8.1VAC $\times 0.74 \mathrm{~A} \times \sqrt{3} \times 0.8=8.3 \mathrm{~W}$ \\
No-load output & $190 \mathrm{VAC}$ \\
Load input & $8.5 \mathrm{VAC} \times 2.29 \mathrm{~A} \times \sqrt{3} \times 0.8=26.9 \mathrm{~W}$ \\
Load 1923 rpm output & $252 \mathrm{VAC} \times 0.138 \mathrm{~A}=34.9 \mathrm{~W}$ \\
elf & $34.9 \mathrm{~W} \div 26.9 \mathrm{~W}=129.7 \%$ \\
Power consumption & $26.9 \mathrm{~W}-8.3 \mathrm{~W}=18.6 \mathrm{~W}$ \\
Net power & $34.9 \mathrm{~W}-18.6 \mathrm{~W}=16.3 \mathrm{~W}$ \\
Net output & $16.3 \mathrm{~W}-8.3 \mathrm{~W}=+8 \mathrm{~W}$ \\
\hline
\end{tabular}




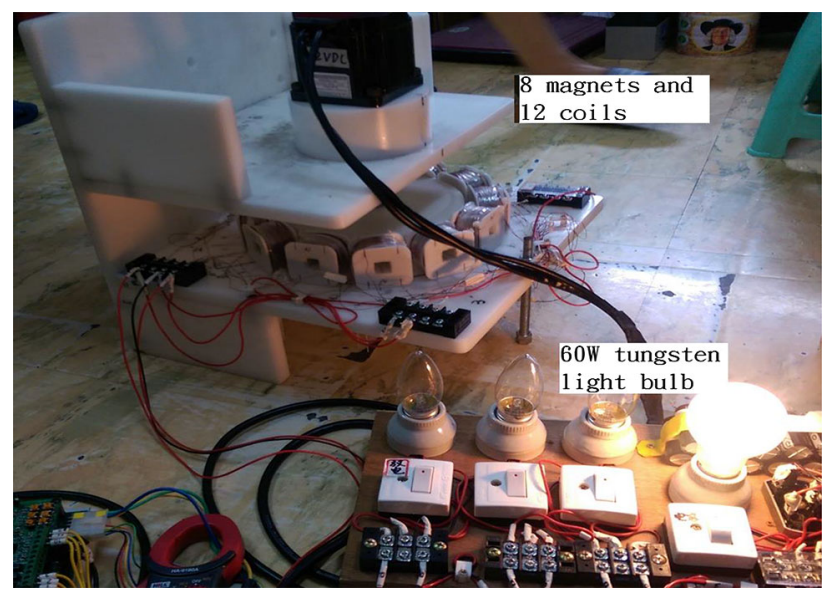

Fig. 11 Use 8 magnets and 12 coils for three-phase power generation entity

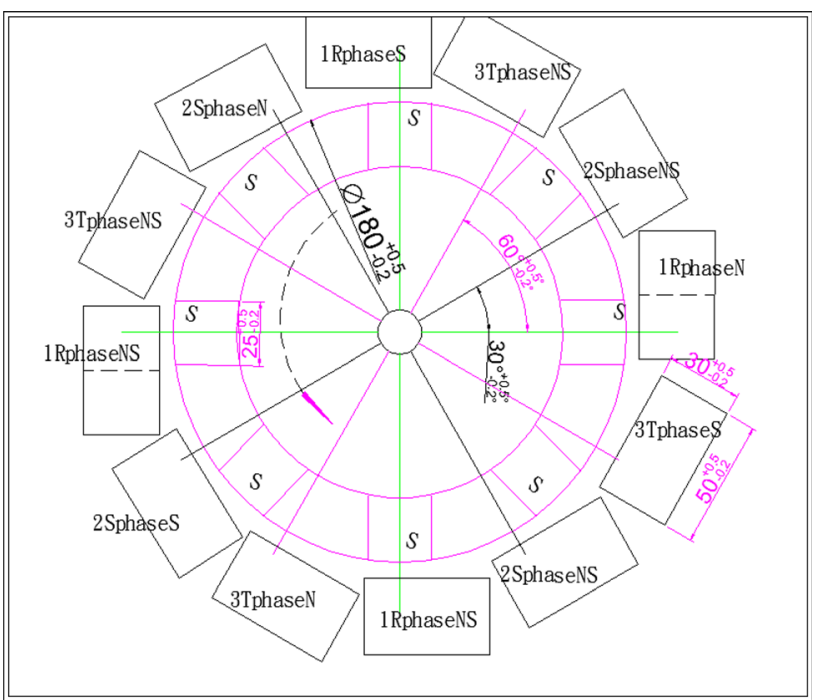

Fig. 12 Arrangement of three-phase power generation coils

As can be seen from Table 5, with an input of $86.1 \mathrm{~W}$, the generator with 8 magnets and 12 longitudinal arrangement-based coils in three-phase $\mathrm{Y}$ connection achieves an output of $51.23 \mathrm{~W}$, indicating the three-phase delta connection and three-phase $\mathrm{Y}$ connection generate the same amount of power.

\subsubsection{Difference in benefit between single-wire wound and six-wire wound coils in three-phase magnetic power generators}

As can be seen in Fig. 15, the six-wire wounds S1-S6 are grouped with N1-N6, respectively. First, N1, N2, N3, N4, and N5 are connected with S2, S3, S4, S5, and S6, respectively, where $\mathrm{S} 1$ is connected with the otherN6, and N6 is connected with the other S1 (Shoji et al. 2003).
Three-phase 8 magnet 12 coil triangle connection method

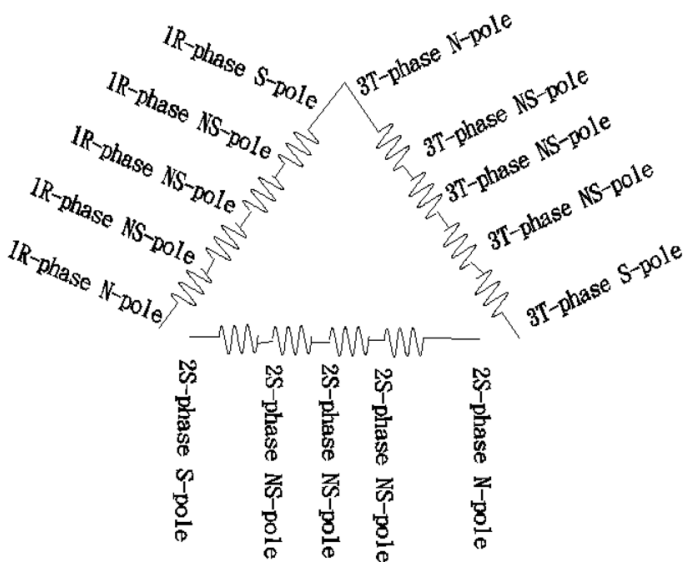

Fig. 138 magnets and 12 coils in three-phase delta connection

\subsubsection{Test 6: Three-phase generator in delta connection}

Test 6: A generator with single-wire wound coils in threephase delta connection is tested for rectification efficiency.

As can be seen from Table 6, with an input of $81 \mathrm{~W}$, the generator with single-wire wound coils in three-phase delta connection and with a rectification function enables an output of $56 \mathrm{~W}$. The efficiency is $69 \%$, indicating that efficiency of a generator with rectification is higher than that of a generator without rectification.

\subsubsection{Test 7: Three-phase generator in delta connection}

Test 7: Six-wire wound coils in three-phase delta connection are tested for rectification efficiency.

As can be seen in Table 7, with an input of $74.9 \mathrm{~W}$, the generator with six-wire wound coils in three-phase delta connection and with a rectification function enables an output of $61.56 \mathrm{~W}$. The efficiency is up to $82 \%$, indicating that the six-wire wound coils could achieve higher efficiency than the single-wire wound coils.

\section{Results and discussion}

\subsection{What is difference between a magnetic power generator and a conventional generator? How to prove that the magnetic power generator has higher efficiency?}

1. The traditional generator is composed of two sets of coils to form an AC loop, which causes two resistances to enter and pull away during the power generation process; but the magnetic power generator has one coil 
Table 4 Results of high-efficiency output three-phase delta connection of magnetic power generator

\begin{tabular}{llll}
\hline Low power load & \multicolumn{2}{l}{ Tungsten light bulb } & RT-phase \\
\cline { 2 - 3 } Phase type & RS-phase & ST-phase & $40 \mathrm{~W}$ \\
\hline Load watt-age & $40 \mathrm{~W}$ & $40 \mathrm{~W}$ & $178 \mathrm{VAC}$ \\
Load speed & $1571 \mathrm{rpm}$ & $182 \mathrm{VAC}$ & $64.7 \mathrm{VAC} \times 0.26=16.8 \mathrm{~W}$ \\
No-load voltage & $183 \mathrm{VAC}$ & $71.0 \mathrm{VAC} \times 0.24 \mathrm{~A}=17.04 \mathrm{~W}$ & \\
Power output & $70.4 \mathrm{VAC} \times 0.26 \mathrm{~A}=18.3 \mathrm{~W}$ & \\
Total & $18.3 \mathrm{~W}+17.04 \mathrm{~W}+16.8 \mathrm{~W}=52.14 \mathrm{~W}$ & \\
Power input power & $8.34 \mathrm{VAC} \times 7.46 \mathrm{~A} \times \sqrt{3} \times 0.8=86.2 \mathrm{~W}$ & \\
elf & $52.14 \mathrm{~W} \div 86.2 \mathrm{~W}=60 \%$ & & \\
\hline
\end{tabular}

Three-phase 8 magnet 12 coil Star type connection method

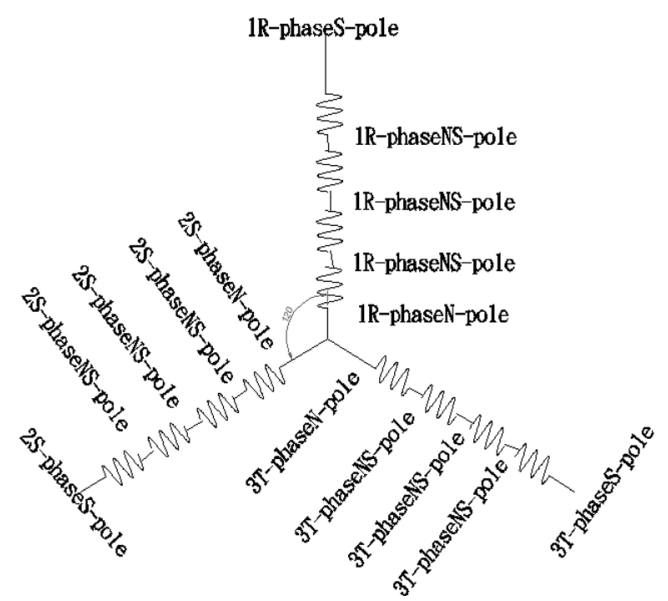

Fig. 148 magnets and 12 coils in three-phase $\mathrm{Y}$ connection

fprming an AC loop, so the entry resistance and the exit tension can be reduced.

2. The traditional generator has a maximum efficiency of $70 \%$, but the magnetic power generator has $82 \%$ of the low power load test in three-phase power generation

\section{Straight Line Six Line Connection}

Connect the N6 side of his line

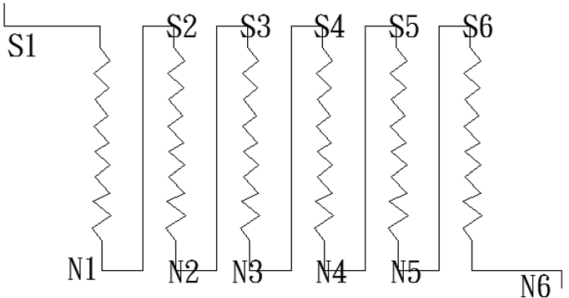

Connect the S1 side of his line

S1 is beginning of the line

$\mathrm{N} 6$ is ends of the line

Fig. 15 Three-phase coils in six-wire winding connection

test7, so the magnetic power generator is more efficient.

\subsection{Difference in benefit between single-phase magnetic power generators in and not in an angle transformation}

Figure 16 shows that the single-phase magnetic power generator with coils in an angle transformation

Table 5 Results of high-efficiency output three-phase Y connection of magnetic power generator

\begin{tabular}{llll}
\hline Low power load & \multicolumn{2}{l}{ Tungsten light bulb } & ST-phase \\
\cline { 2 - 4 } Phase type & RS-phase & $40 \mathrm{~W}$ & $40 \mathrm{~W}$ \\
\hline Load watt-age & $40 \mathrm{~W}$ & & $181 \mathrm{VAC}$ \\
Load speed & $1577 \mathrm{rpm}$ & $179 \mathrm{VAC}$ & $65 \mathrm{VAC} \times 0.25 \mathrm{~A}=16.25 \mathrm{~W}$ \\
No-load voltage & $183 \mathrm{VAC}$ & $71 \mathrm{VAC} \times 0.24 \mathrm{~A}=17.04 \mathrm{~W}$ & \\
Power output & $69 \mathrm{VAC} \times 0.26 \mathrm{~A}=17.94 \mathrm{~W}$ & \\
Total & $17.94 \mathrm{~W}+17.04 \mathrm{~W}+16.25 \mathrm{~W}=51.23 \mathrm{~W}$ & \\
Power input power & $8.37 \mathrm{VAC} \times 7.43 \mathrm{~A} \times \sqrt{ } 3 \times 0.8=86.1 \mathrm{~W}$ & \\
elf & $51.23 \mathrm{~W} \div 86.1 \mathrm{~W}=59.5 \%$ & & \\
\hline
\end{tabular}


Table 6 Results of high-efficiency output of three-phase single-wire wound magnetic power generators, and comparison of difference between generators with and without three-phase rectification

\begin{tabular}{ll}
\hline Low power load & Tungsten light bulb \\
\hline Load wattage & $60 \mathrm{~W}$ \\
Load speed & $1600 \mathrm{rpm}$ \\
No-load voltage & $248 \mathrm{VDC}$ \\
Power output & $112 \mathrm{VDC} \times 0.5 \mathrm{~A}=56 \mathrm{~W}$ \\
Power input power & $8.2 \mathrm{VAC} \times 7.13 \mathrm{~A} \times \sqrt{3} \times 0.8=81 \mathrm{~W}$ \\
elf & $56 \mathrm{~W} \div 81 \mathrm{~W}=69 \%$ \\
\hline
\end{tabular}

Table 7 Results of high-efficiency output of three-phase six-wire wound magnetic power generator, and comparison of power generation of single-wire wound and six-wire wound generators

\begin{tabular}{ll}
\hline Low power load & Tungsten light bulb \\
\hline Load wattage & $60 \mathrm{~W}$ \\
Load speed & $1639 \mathrm{rpm}$ \\
No-load voltage & $219 \mathrm{VDC}$ \\
Power output & $108 \mathrm{VDC} \times 0.57 \mathrm{~A}=61.56 \mathrm{~W}$ \\
Power input power & $8.2 \mathrm{VAC} \times 6.6 \mathrm{~A} \times \sqrt{ } 3 \times 0.8=74.9 \mathrm{~W}$ \\
elf & $61.56 \mathrm{~W} \div 74.9 \mathrm{~W}=82 \%$ \\
\hline
\end{tabular}

arrangement requires a lower input and enables a higher output, representing an increase of efficiency of $40 \%$.

\subsection{How the single-phase power generation does uses the best combination of angle transformations with an efficiency of $129.7 \%$. How does it measure? Is it a violation of energy conservation?}

1. The eddy current generated by the generator is interrupted by the angle change of the coil in each turn to reduce the drag, so the single-phase power generation can reach $129.7 \%$ efficiency.

2. The voltage value is measured in parallel with the voltmeter, and the current value is measured in series with the ammeter, and test load using high power Led lights.

3. The single-phase angle transformations magnetic power generator uses the special arrangement of coil to make the force of the magnet to generate the thrust and to achieve the energy-saving effect. Therefore, the highest efficiency of $129.7 \%$ includes the force of the magnet itself and the input of the motor does not violate the energy conservation.

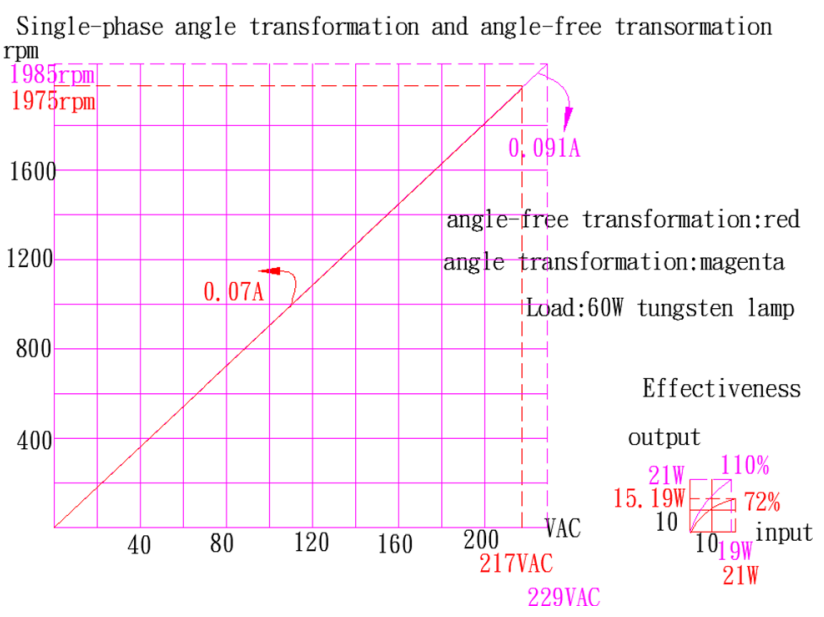

Fig. 16 Curve analysis of single-phase magnetic power generators in and not in an angle transformation arrangement

\subsection{Difference the maximum efficiency between the single-phase magnetic power generator with reverse-phase coils and coils in an angle transformation arrangement with domestic and foreign generator manufacturers}

As can be seen in Table 8, the single-phase magnetic power generator with reverse-phase coils increase efficiency by $30 \%$ compared to domestic or foreign generator manufacturers.

\subsection{Whether the three-phase magnetic power generator is suitable for the angle transformation? How to improve the driving force of the driving again in the future if the single-phase angle transformations magnetic power generator is applied to an electric vehicle?}

1. Since each phase in three phases is a single phase and the independent of each phase, so the angle conversion method is applied to improve the efficiency in threephase magnetic power generator.

2. Single-phase angle transformations magnetic power generator can be used with the flywheel and with small motor as the power of the electric vehicle, the principle is that a lithium battery is used to provide DC small motor power, the DC small motor drives the flywheel, the flywheel drives the magnetic assisted generator and electric vehicle provides the power, because the highfrequency synchronous power generation generated by the magnetic power generator can be supplied to the power of a power coil added inside the magnetic power generator. The power generation and power functions 
Table 8 Maximum efficiency performance analysis

\begin{tabular}{llll}
\hline $\begin{array}{l}\text { Object } \\
\text { comparison }\end{array}$ & This paper experiment & $\begin{array}{l}\text { Domestic manufacturers http://www.jihdah. } \\
\text { com/showinvestors.asp?investorsId= } \\
\text { I013040001211212 }\end{array}$ & $\begin{array}{l}\text { Foreign manufacturers https://www.cadmen.com/ } \\
\text { page/iFrame/Preview.aspx?tp=News\&im= } \\
51 \& n s=148\end{array}$ \\
\hline Efficiency & $\begin{array}{c}\text { Single-phase magnetic } \\
\text { power generator } \\
\text { efficiency 129.7\% }\end{array}$ & JIH-DAH,LTD maximum efficiency 98\% & INDAR Electric maximum efficiency 97.7\% \\
$\begin{array}{c}\text { Test motor } \\
\text { type }\end{array}$ & $\begin{array}{c}\text { 300 W DC brushless motor } \\
\text { and magnetic power } \\
\text { generator }\end{array}$ & $\begin{array}{c}\text { SEMA-T468 motor 3600 RPM max power } \\
\text { 160 HP }\end{array}$ & Permanent magnet generators (PMGs) \\
$\begin{array}{c}\text { Control } \\
\text { method }\end{array}$ & $\begin{array}{l}\text { Brushless Speed regulation } \\
\text { Segmented electromagnetic array construction }\end{array}$ & Low frequency An soft Maxwell \\
\hline
\end{tabular}

of the magnetic power generator can reduce the load driven by the DC small motor, and the power generation is rectified and recharged to another battery, which improves the higher endurance of the vehicle.

\subsection{Difference in benefit between three-phase single-wire wound and three-phase six-wire wound magnetic power generators}

Figure 17 indicates that the six-wire wound generator achieves efficiency that is $13 \%$ higher than its single-wire wound counterpart when using low power loads.

\subsection{What is the function of the three-phase magnetic assisted generator in the six-line tangling? How is it different form using three or more lines?}

1. The function of the three-phase magnetic power generator reduces the cutting resistance by reducing the number of turns per single line by six-wire winding method and to reduce the input when using low power loads for example using a tungsten light bulb as a load.

2. It has been tested that the odd number six-wire tangling method is more efficient than the even-numbered line or the three-line or twelve-line number, so odd number six-wire tangling efficiency is highest under low power load.

\subsection{How to improve single-phase and three- phase magnetic power generators in the future}

\subsubsection{Improvement of single-phase magnetic power generators}

As shown in Fig. 18, in the single-phase magnetic power generator with coils in angle transformation arrangement,

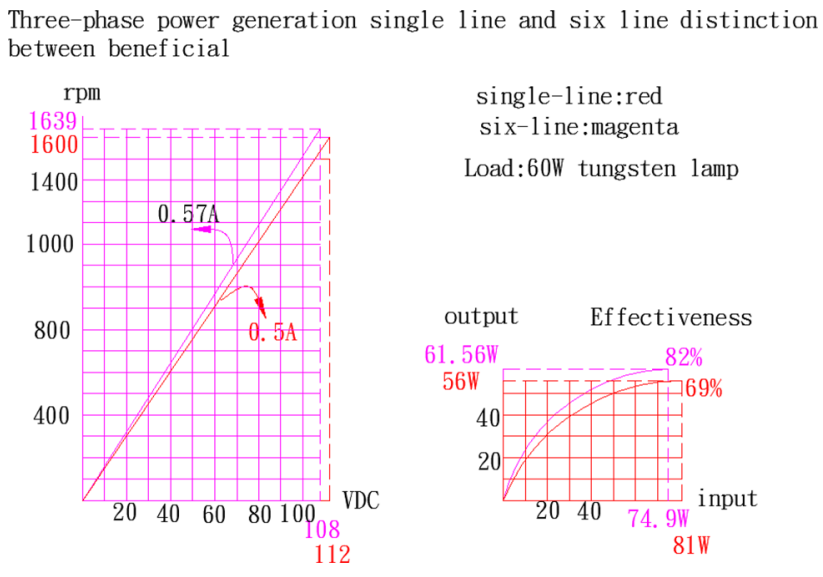

Fig. 17 Curve analysis of three-phase magnetic power generators in the single-wire wound and six-wire wound configuration

the diameter and length of the magnets are increased from 25 to $30 \mathrm{~mm}$ to increase the cutting area and magnet strength (Mizutani et al. 2004).

\subsubsection{Improvement of three-phase magnetic power generator}

Figure 19 shows that increasing the number of magnets from 8 to 16 results in an increase in the magnetic field strength (Lateb et al. 2006).

As shown in Fig. 20, increasing the number of magnets from 8 to 16 , increasing the number of coils from 12 to 24 , and using three-phase or six-phase connection configuration can increase the magnetic field strength and power generation (Che et al. 2014).

As shown in Fig. 21, the power generation of the generator with 8 magnets 12 coils is increased by using the double-sided vertical cutting method (Jansen et al. 2006).

Outlook: Currently the efficiency of a single-phase magnetic power generator with coils in an angle transformation arrangement has been $129.7 \%$. With both the magnet diameter and length increased to $30 \mathrm{~mm}$, 
respectively, the efficiency could be increased to $140 \%$. Currently, a three-phase six-wire wound power generator could output power of $61.56 \mathrm{~W}$, where the diameter of the wire is $0.4 \mathrm{~mm}$. In future, the power could be increased to over $100 \mathrm{~W}$ using wires with a diameter of $0.5 \mathrm{~mm}$ in conjunction with using the said 3 methods (Fig. 21).

\section{Conclusion}

\subsection{Using thin wire in power generation coils is likely to cause high impedance and generate low current}

Therefore, it needs to determine the load voltage before the maximum power generation current is determined.

\subsection{A large magnetic force increases the power generation}

The magnetic field strength determines wire diameter, wire diameter determines the impedance value, and the impedance value determines the power generation voltage. Large impedance requires a high power generation voltage but causes a low power generation current, which causes a large motor load.

\subsection{The connection configurations of the three- phase magnetic power generator should be selected according to the load voltage}

If the three-phase Y connection configuration is selected, line voltage is higher than phase voltage and line current is

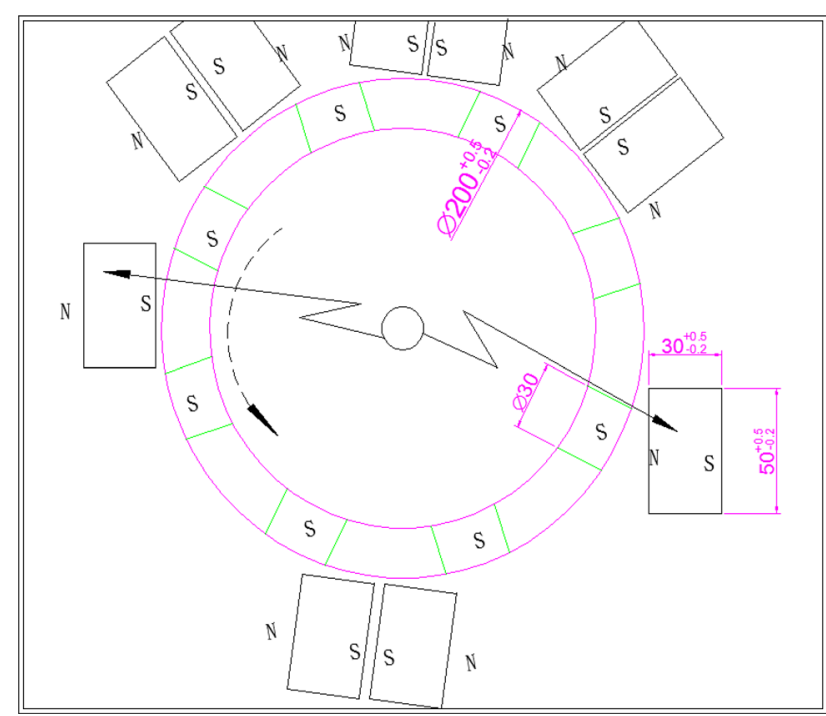

Fig. 18 Increase of cutting area and magnet strength for the singlephase magnetic power generator

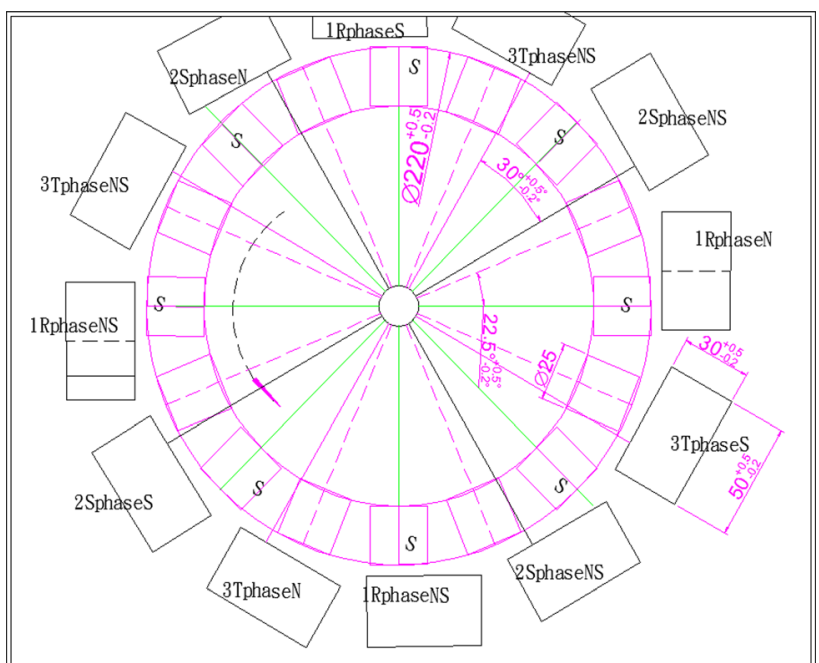

Fig. 19 Increasing 8 magnets to 16 magnets

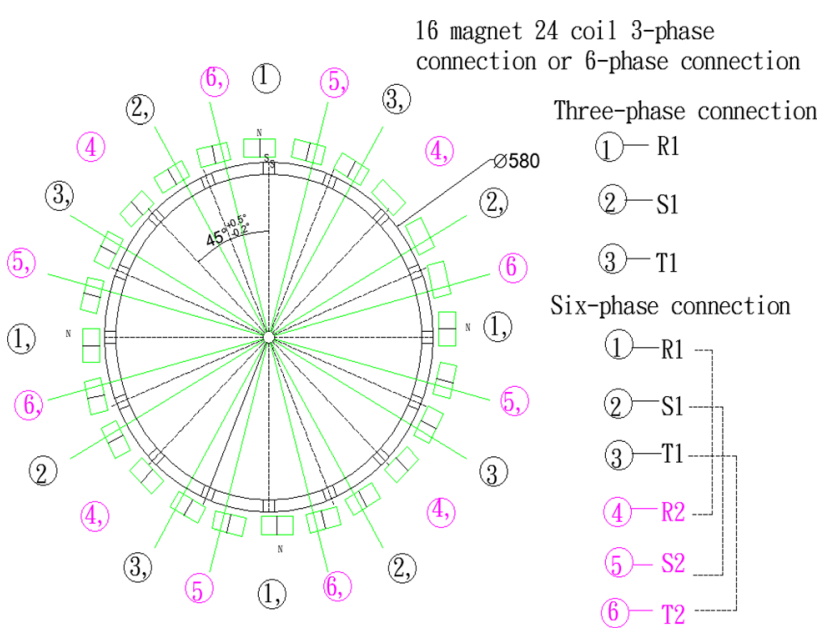

Fig. 20 Power output of a six-phase generator with 16 magnets and 24 coils

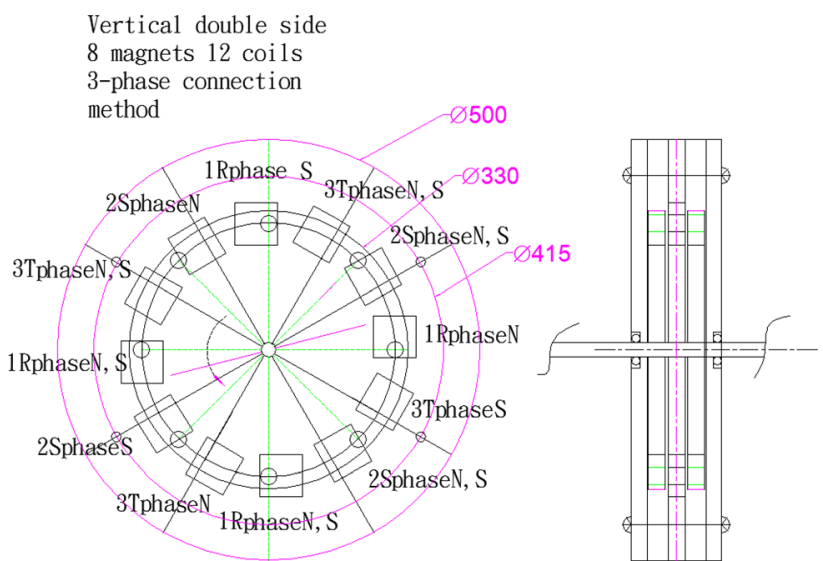

Fig. 21 Using a double-sided vertical cutting method to generate power for three-phase generators 
equal to phase current. Due to a high working voltage, thick line is suitably used. If the three-phase delta connection configuration is used, line voltage is equal to phase voltage and line current is larger than phase current. Thus thin-wire wound coils can be used to generate electricity.

\subsection{Advantages of single-phase magnetic power generators with coils in an angle transformation arrangement}

1. Single-phase magnetic power generators with coils in an angle transformation arrangement achieve higher efficiency and are more suitable for general household use.

2. They can be used in conjunction with power generated by electric vehicles to increase driving endurance.

3. They can be used in conjunction with wind power. A force 2 wind can enable a full-load power generation, which increase the popularity of single-phase magnetic power generators with coils in an angle transformation arrangement.

\subsection{Advantages of three-phase six-wire wound magnetic power generator}

1. The three-phase $\mathrm{Y}$-connection configuration can simultaneously generate three-phase $220 \mathrm{~V}$ AC and $440 \mathrm{~V}$ AC current, and the three-phase delta connection configuration can generate three-phase $220 \mathrm{~V}$ AC current, which is suitable for general industrial use.

2. The three-phase magnetic power generator adopting the 6 wire winding configuration can enable a small load input and a high power output under low power load.

3. With only 4 coils generating power in each phase, the coils cause less interference with each other. Thus the three-phase magnetic power generator achieves a high power output.

\subsection{How does the publication of this paper give inspiration to the researcher and contribute to society?}

1. For those who want study the high efficiency generator, they can understand the principle and data analysis through the experimental process, and can quickly go to a higher level development.

2. Currently the worldwide faces power shortages, and hopes that this study can reduce the problem of power shortage and create social happiness with low-cost electricity.

Open Access This article is distributed under the terms of the Creative Commons Attribution 4.0 International License (http://creative commons.org/licenses/by/4.0/), which permits unrestricted use, distribution, and reproduction in any medium, provided you give appropriate credit to the original author(s) and the source, provide a link to the Creative Commons license, and indicate if changes were made.

\section{References}

Che Hang Seng et al (2014) Operation of a six-phase induction machine using series-connected machine-side converters. IEEE Trans Industr Electron 61(1):164-176

Cheng K, Evans P (1994) Calculation of winding losses in highfrequency toroidal inductors using single strand conductors. IEE Proc Electric Power Appl 141(2):52-62

Cheng $\mathrm{M}$ et al (2011) Overview of stator-permanent magnet brushless machines. IEEE Trans Industr Electron 58(11):5087-5101

Ishak D et al (2004) Permanent magnet brushless machines with unequal tooth widths and similar slot and pole numbers. In: Conference record of the 2004 IEEE industry applications conference, 2004. 39th IAS Annual Meeting, IEEE

Jansen PL et al (2006) Electrical machine with double-sided rotor: Google Patents

Konrad B (1992) Electronic electricity meter: Google Patents

Lateb R et al (2006) Effect of magnet segmentation on the cogging torque in surface-mounted permanent-magnet motors. IEEE Trans Magn 42(3):442-445

Mizutani U et al (2004) Magnetron sputtering activated by a $60 \mathrm{~mm}$ diameter superconducting bulk magnet. Supercond Sci Technol 18(2):S30

Ooiwa T (2003) Vehicle AC generator: Google Patents

Saha CR et al (2006) Optimization of an electromagnetic energy harvesting device. IEEE Trans Magn 42(10):3509-3511

Salmeron P, Litran SP (2010) A control strategy for hybrid power filter to compensate four-wires three-phase systems. IEEE Trans Power Electron 25(7):1923-1931

Shoji Y et al (2003) Heat transfer enhancement in round tube using wire coil: influence of length and segmentation. Heat Transfer 32(2):99-107

Siclafi M et al (1993) Aerodynamic analysis of the grumman maglev vehicle. In: Proc of Maglev'93, 13th Int Conf" on magneticallylevitated systems and linear drives

Sreenivasarao D et al (2012) Neutral current compensation in threephase, four-wire systems: a review. Electric Power Systems Research 86:170-180

Zhang C, Tang W (2014) Theoretical comparison, equivalent transformation, and conjunction operations of electromagnetic induction generator and triboelectric nanogenerator for harvesting mechanical energy. Adv Maters 26(22):3580-3591

Publisher's Note Springer Nature remains neutral with regard to jurisdictional claims in published maps and institutional affiliations. 